\title{
Surge in Procalcitonin Levels Post ATG During Stem Cell Transplantation for Aplastic Anemia: A Diagnostic Dilemma with Sepsis?
}

\author{
Garg A*, Patel K, Shah K, Raj A and Shah S \\ BMT Division, Department of Medical Oncology, The \\ Gujarat Cancer and Research Institute, Ahmedabad, \\ India \\ *Corresponding author: Akanksha Garg, Assistant \\ Professor, Department of Medical Oncology, The Gujarat \\ Cancer and Research Institute, Ahmedabad, Gujarat, \\ India
}

Received: August 12, 2021; Accepted: October 07, 2021; Published: October 14, 2021

\section{Letter to the Editor}

Allogenic Stem Cell Transplantation (AlloSCT) has paved way for curative therapy in numerous hematologic diseases such as Aplastic Anemia. Anti-Thymocyte Globulin (ATG), a polyclonal T-cell antibody is an integral part of the numerous conditioning regimens. Its purpose is the T-cell depletion of the recipient, which is of utmost importance for the prevention of graft rejection and successful engraftment. Febrile responses after ATG administration pose a diagnostic dilemma in these patients who are frequently neutropenic [1].

During the conditioning phase before AlloSCT, patients undergo substantial immunosuppression and immune-alteration under the effect of pharmacotherapy and total body irradiation. Conditioning with ATG can be associated with febrile episodes, circulatory instability and/or respiratory insufficiency. The severity of this reaction especially in a neutropenic patient can closely resemble sepsis. Since blood cultures can take a few days in reporting, biochemical markers of inflammation, such as C-Reactive Protein (CRP) and Procalcitonin (PCT) levels have a diagnostic value. In contrast to CRP, Procalcitonin is a sensitive and specific marker for systemic bacterial infection and fungal sepsis $[2,3]$.

We observed a surge in procalcitonin levels after ATG administration in a patient suffering from severe aplastic anemia undergoing conditioning for allogenic bone marrow transplantation from a matched sibling donor. The patient weighing 72 kilograms, received rabbit ATG as GVHD prophylaxis at the rate $1.5 \mathrm{mg} / \mathrm{kg}$ ( 5 vials of $25 \mathrm{mg}$ each) on Day - 3 of conditioning and developed high grade fever with chills, reaching a peak temperature of 103.6 degrees Fahrenheit. Microbiological cultures and procalcitonin levels were sent to rule out sepsis as part of the protocol. First line intravenous antibiotics were started and antipyretics were administered. Fever settled on its own once the ATG therapy was completed. On day -2 and -1 , the same dose of ATG was given and the patient did not develop any febrile episodes. The median PCT elevation on day 1 after ATG infusion was $87.68 \mathrm{mcg} / \mathrm{L}$, nearly 70 times the baseline level.
Patient was clinically stable with no features of sepsis. There was a steady decline in PCT levels over the next 4 days, 58.54, 24.79, 4.38 and $1.13(\mathrm{mcg} / \mathrm{L})$ respectively. No derangements in liver function tests or renal function tests were observed. Subsequently, the microbiological cultures were sterile ruling out sepsis.

Several previous reports suggested limited diagnostic value of PCT and CRP in the presence of anti-T-lymphocyte antibodies. Dornbusch et al. compared 15 consecutive febrile episodes after T cell antibody infusion without clinical signs of infection with nine episodes of Gram-negative sepsis. After T-cell antibody infusion PCT and CRP serum levels increased to a similar extent as in Gramnegative sepsis. They concluded that during $\mathrm{T}$-cell antibody treatment neither PCT nor CRP are adequate for differentiating between fever due to infection or to unspecific cytokine release. The median PCT elevation on day1 after T-cell antibody infusion was nearly 40 times the baseline [4]. In our patient, the levels reached 70 times the baseline value probably related to higher ATG dose according to the weight of the patient.

Brodska et al., prospectively evaluated the validity of CRP and PCT to diagnose infection in patients receiving ATG prior to hematopoietic stem cell transplantation. They assessed renal and liver functions and their relationship to PCT and CRP changes. They found no interrelationship between PCT levels and BL markers of renal or liver functions ( $\mathrm{P}>0.05$ for all comparisons) [5]. Similarly in our patient, no derangements in LFT or RFTs were seen.

To conclude, febrile episodes during treatment with ATG are associated with markedly elevated levels of PCT directly proportional to the dose of ATG given. This causes a diagnostic dilemma with sepsis and early use of antimicrobials, which may be kept in reserve during actual crisis in the post-transplant period. In such a scenario, detailed clinical assessment of patient's condition and careful interpretation of biochemical and microbiological investigations is of utmost importance for judicious use of antimicrobials in this era of emerging antibiotic resistance.

\section{References}

1. Dearden C, Foukaneli $T$, Lee $P$, et al. The incidence and significance of fevers during treatment with antithymocyte globulin for aplastic anaemia. $\mathrm{Br} \mathrm{J}$ Haematol. 1998; 103: 846-848.

2. Müller B, Becker KL, Schächinger H, Rickenbacher PR, Huber PR, Zimmerli $\mathrm{W}$, et al. Calcitonin precursors are reliable markers of sepsis in a medical intensive care unit. Crit Care Med. 2000; 28: 977-983.

3. Nargis W, Ibrahim MD, Ahamed BU. Procalcitonin versus C-reactive protein: usefulness as biomarker of sepsis in ICU patient. Int J Critllln Inj Sci. 2014; 4: 195-199.

4. Dornbusch HJ, Strenger V, Kerbl R, Lackner H, Schwinger W, Sovinz P, et al. Procalcitonin and $\mathrm{C}$-reactive protein do not discriminate between febrile 
reaction to anti-T-lymphocyte antibodies and Gram-negative sepsis. Bone Marrow Transplant. 2003; 32: 941-945.

5. Brodska H, Drabek T, Malickova K, Kazda A, Zima T, Markova M, et al.
Marked increase of procalcitonin after the administration of anti-thymocyte globulin in patients before hematopoietic stem cell transplantation does not indicate sepsis: a prospective study. Critical Care. 2009; 13: R37. 